\title{
Sexism in ESL Textbooks in Sri Lanka: A Case Study of the G.C.E. O/L Textbooks
}

\author{
L.M.S. Wijetunga* \\ Department of English, University of Colombo
}

\begin{abstract}
As per the Sapir-Whorf theory, languages determine thought. Thus, whatever the atmosphere created by a language, be it first or second, determines the outlook of the learner towards the society. Textbooks are a key factor in exposing learners to a new language, especially in Sri Lanka, where the majority of the lesson time in English is allocated for studying the textbook. It then becomes imperative that the textbooks be analysed for their use of language as textbooks are often the only mode through which learners get to view the world associated with the English language. Textbooks prescribed by the Ministry of Education for grades 9, 10 and 11 were therefore analysed using a combination of quantitative and qualitative methodologies. The purpose was to determine whether the textbooks were partial to one gender or sex and if so, understand in what way it was biased. It was identified that there are clear demarcations of sexism in the texts analysed, with the males being given a dominating, powerful and central role while females were relegated to a secondary supportive role. It was also identified that representation of female role models was inadequate and severely out of date. The findings have considerable implications in that the female students studying these texts would not only be unable to relate to the content, leading to poorer performance in studies but also in that the females would be embedded with the incorrect notion that the role of a woman is secondary. This trend could have a grave impact in terms of creating the next generation of Sri Lanka as the exposure provided to the learners does not expose them to a more gender-sensitive society.
\end{abstract}

\footnotetext{
*Corresponding Author: L.M.S. Wijetunga; email: minoliwijetunga@gmail.com ORCiD: http://orcid.org/0000-0003-0756-9841

(Received 31 March 2017; Revised 08 June 2017; Accepted 20 July 2017)

(c) OUSL
} 
Keywords: Sexism, Textbooks, Education, Syllabus, Teaching

\section{Introduction}

A topic that has been much contended in Sri Lanka during recent times is the status of the female. While the woman is admired and appreciated as a mother, her representation as anything beyond motherhood is often questioned. Although Sri Lanka was the country to produce the first female prime minister, it was "without disturbing the general patterns of subordination" (Jayawardena, 1986; 2009, p. 133). As children are but the future of a nation, the future of the feminist movement (or the lack thereof), it is important to investigate the ideologies and conceptual framework that shape the perception of the young. While English as a Second Language (ESL) textbooks are but one of the many forms of influence, it is an important one in that English is often perceived to be the "link" to the world outside the island nation, thereby providing a window to a broader view of the world. Thus, this study aims to investigate the content of ESL textbooks in Sri Lanka to identify the gender-related ideologies they encompass.

\section{Theoretical Framework}

"Human beings do not live in the objective world alone... but are very much at the mercy of the particular language which has become the medium of expression for their society." (Sapir as cited in Werner, 1997, p. 77)

Language is not merely a tool for communication. Language is also a means of establishing and sustaining relationships within a speech community. In sociolinguistic terms, all aspects of language must be seen through the prism of the society in which speakers live and function as language is not an independent entity. Although the subject of much linguistic and anthropological debate, Sapir-Whorf hypothesis follows the premise that it is language that shapes one's thoughts (Werner, 1997). Substantiating this purview of language is Fairclough's (2001) Critical Discourse Analysis application, which identifies language as having a dialectical relationship with social practices. This relationship between a language and social practices that shape an individual's perception of the world is an underlying cornerstone of second language learning. If language, indeed, is responsible for opening up a new perspective to the world an individual occupies, having 
the knowledge of an additional language allows the individual to explore the same world in a novel manner. Thence, the nature of language that a learner is exposed to becomes crucial. If a learner is exposed to a language that is prejudiced in some form, it naturalises the prejudice (Pavlenko, Blackledge, Piller, \& Teutsch-Dwyer, 2001) shaping the world of the learner through the said prejudice. If an individual immerses his/herself in a language that is racist, sexist, homophobic, or discriminating in any manner, it could be argued that they would discern the world through a discriminatory lens.

Sexism is part of the capitalist ideology which advocates male supremacist values. These values define the nature of women and men in respect to being superior or inferior. Men are defined as "naturally" stronger, more logical, and able to economically provide for others. Women are defined as "naturally" dependent, childlike, and therefore always in need of authority. (NietoGomez, 1997;2014, p. 97)

Sexism and gender representation is a topic that is heavily debated in today's context. It has been identified that gender is an entity that has often been described a binary, assigning each of the duo a clear set of characteristics. According to NietoGomez $(1997 ; 2014)$, sexism in this day has transitioned from mere "advocating" to the forcing of 'masculine' characteristics upon men and 'feminine' characteristics upon females; Further, gender is no longer seen as a binary, but as a spectrum within which one can choose to oscillate or not. With the onset of Queer theory and Masculine studies, this binary that is socially propagated becomes problematic.

In this context, this paper investigates gender representation in a selection of ESL textbooks in Sri Lanka. Textbooks have a central role to play in education in that they are one of the cheapest and most effective ways of transforming knowledge and values (Esen, 2007). Taylor (2003) emphasises that textbooks and media are crucial in the shaping of a child's perception of the world. Thus, it is important that the textbooks portray the reality or the desired reality in order to ensure that children are not led to believe the existence of a world that is imaginary. Therein lies the significance of gender equality or lack thereof in textbooks. It has been identified that in countries where the education system is mostly exam oriented, approximately $95 \%$ of classroom time is exercised in perusing the textbooks (Tao, 2008). According to Wolf (2007), reading is a major influence in the evolution of the brain 
through assimilation of information. Therefore, it stands to reason that if a child spends a significant portion of her/his time consuming a text that promotes sexism, it is inevitable that the "value" that is transmitted is "sexism is normal and natural"; similarly, if the text attempts to eradicate inequality and treat all individuals as equal, it would inculcate a positive attitude in the child, as the child would be assimilating and processing this new information. The school is more often than not the only place where an average child is exposed to English (Perera, 2010), which holds true for Sri Lanka as well. Being a compulsory subject from grade 3 to grade 13, English is imparted to the majority of the children through textbooks provided by the government.

Sri Lanka, being an Asian country, a developing country as well as a country that boasts of its age-old traditions and culture, has not had its ESL textbooks analysed for the existence of sexism, as far as this researcher could discover. It was deemed necessary that textbooks_of the Sri Lankan education system are examined for their use of language due to the dire implications a biased language and a biased representation of women would pose to a young learner. Therefore, this research investigates the gender representation of the text provided for ESL textbooks for the GCE O/L to determine if they are sexist or not.

\section{Textbook analysis in a global context}

The first wave of feminist campaigners in the mid-1900's in the European region triggered the inspection of written material for sexism in language. The most notable writings that set in motion the study of textbooks are "Sexism in TESOL materials" by Hartman and Judd (1978); "For Men Must Work and Women Must Weep: Sexism in English Language Textbooks Used in German Schools" by Hellinger (1980); and Porreca's (1984) "Sexism in Current ESL Textbooks". Initiated as such, sexism in textbooks has been a frequent topic of research in all regions of the world (Ansari \& Babii, 2005; Bahman \& Rahimi, 2010; Ebadi, 2015; Esen, 2007; Evans \& Davies, 2000; Ndura, 2004; Porreca, 1984; Tao, 2008), often following at least some of the broad categories introduced by Hartman and Judd (1978) in their initial study.

One of the most frequent methods of investigating sexism in the textbooks has been gender visibility. In Porreca's study of 15 textbooks used by ESL centres in the USA, the number of occurrences of females to males was 
1:2.06 (Porreca, 1984). Similar conditions were reported in textbooks for senior high school students in China, where 27 out of 33 protagonists of the texts were male (Tao, 2008). Tao (2008) also notes the lack of historical female figures in the text ( 18 males as opposed to 4 females) is likely to lead to female students being demotivated. In 2005 study conducted in Iran, the ratio of female to male occurrence in texts was 1:1.4 (Ansary \& Babaii, 2005) while the 2010 study showcases males to consume $76.43 \%$ of the occurrences while females are left at 23.57\% (Bahman \& Rahimi, 2010). As Porreca (1984) observes, when females are not represented as often as males in the textbooks, the implication that is received by the young learner is that female accomplishment are not sufficient to be granted recognition.

Illustrations in the textbooks, as per research, have followed a pattern similar to occurrences in all the aforementioned studies. Esen (2007), investigating illustrations alone, categorises the illustrations to demonstrate that for every female character illustrated as working, twice the amount of men in a working role is portrayed (females: 172; males: 362). In Chinese textbooks, females are illustrated in roles of cooking in the kitchen and shopping for clothes, while male illustrations are of outdoor, adventurous activities (Tao, 2008).

Masculine generic constructions, i.e. instances where a male pronoun is used to indicate universality, demonstrates the ideology that male is the default sex. This trend has been recorded in ESL textbooks in USA (Porreca, 1984), China (Tao, 2008), and Iran (Ansary \& Babaii, 2005). Iranian textbooks have also been identified by the researchers Bahman and Rahimi (2010) as embracing an abundant use of male generic terms as if human beings were only male.

In the USA, the ratio of female to male firstness was at a 1:2.96, where some of the female firstness (such as "your girlfriend/boyfriend") was attributed to the text speaking to a predominantly male audience (Porreca, 1984). Tao (2008), and Ansary and Babaii (2005) discovered that males were always mentioned first in Chinese and Iranian textbooks. However, recent studies on Iranian textbooks suggest a possibility of alteration as evident by the $89.6 \%$ of male firstness while females are mentioned first $10.4 \%$ in the text (Ebadi, 2015). 
In instances where language is deemed sexist, professions are unmarked for males while being marked for females exhibiting that male is the norm. Textbooks of USA, Iran as well as China were discovered to perpetuate marked language for females in that "woman" was added to the profession, even though the further reading of the paragraph would clarify the sex of the character (Porreca, 1984). The most unbalanced ratio of female to male ratio was discovered in occupational roles of each sex in USA textbooks, which was 1:5.87. All female occupations were mentioned in a single chapter titled "Women's Liberation: The Search for Equality" (Porreca, 1984). Tao (2008), analysing the ESL textbooks in China, encountered a wider range of occupations for men that were "demanding, adventurous, high-paying" such as explorer, physicist, politician and athlete. Female occupational roles were mostly restricted to offices, such as being a typist, doctor, nurse, teacher, cook and cleaner. A similar trend was observed in Iranian textbooks as well (Ansary \& Babaii, 2005). Interestingly, the only instance where a female was depicted as an engineer in these Chinese textbooks has been to describe a situation where she faces the risk of losing her job due to her sex being revealed (Tao, 2008).

Character attributions of males and females can demarcate sexism through the features bestowed upon each sex. Porreca (1984) discovered numerous instances of stereotyping and a number of sexual innuendos in the textbooks of USA. Females are also attributed with maternal characteristics, being dependent on men and being overly concerned with appearance (Tao, 2008). It was further noted that adjectives used for females were more in line with their physical appearance and attractiveness ("pretty", "beautiful") 3.4 times more than the same attribution to males (Porreca, 1984). Females were more often described as sitting in the classroom, watching TV, reading, doing dishes and engaging in other such tasks as opposed to males who were playing football, driving a car or riding a bicycle (Ansary \& Babaii, 2005).

Investigation of literature on sexism in textbooks invariably conclude that the textbooks used in ESL/EFL classroom in many parts of the world including East and Middle East Asian region are undoubtedly sexist and promote a notion of discrimination. However, a chronological study of the material does illustrate that the disparity between males and females is gradually narrowed (Ansari \& Babii, 2005; Bahman \& Rahimi, 2010; Ebadi, 2015; Esen, 2007; Evans \& Davies, 2000; Ndura, 2004; Porreca, 1984; Tao, 2008). Thus, this 
study seeks to determine the nature of textbooks used in ESL classroom in Sri Lanka.

\section{Research Methodology}

\section{Research questions}

This research intends to find out whether the text provided as ESL textbooks for the GCE O/L are sexist or not. This broad area of query shall be examined through the following specific research questions:

- Is the visibility of both the genders equal?

- What occupational roles are presented for each gender?

- What family roles are each gender represented in?

- What character attributions are portrayed for each gender?

- What instances of linguistic sexism exist in the textbooks?

\section{Sample}

This research focused on ESL textbooks from three particular grades, namely grades 9, 10 and 11, which lead up to one of the prominent competitive examinations in the country, G.C.E. (O/L)/examination. Grade 9 lays the foundation for this examination, while the content from grades 10 and 11 are directly questioned in the examination. According to Salyers \& McKee (2007), adolescence is the most impressionable age in a child. Thus, the sample selected for this research was based on both the psyche of the learner and the importance of the text within the education system.

English textbooks for grades 9 and 11 comprises two parts, while grade 10 has only one textbook in the new syllabus. These five textbooks were systematically analysed quantitatively as well as a qualitatively in order to investigate whether the content was sexist or not.

\section{Approach}

This research employed most of the criteria introduced by Hartman and Judd (1978) in "Sexism in TESOL materials" to analyse the texts. The approach was a combination of quantitative and qualitative approaches to ensure a holistic analysis. Quantitative analysis was done in categories where the frequency 
was a prominent factor. However, a qualitative aspect was essential to ensure that the study analysed implied ideologies (Ref. Figure 1)

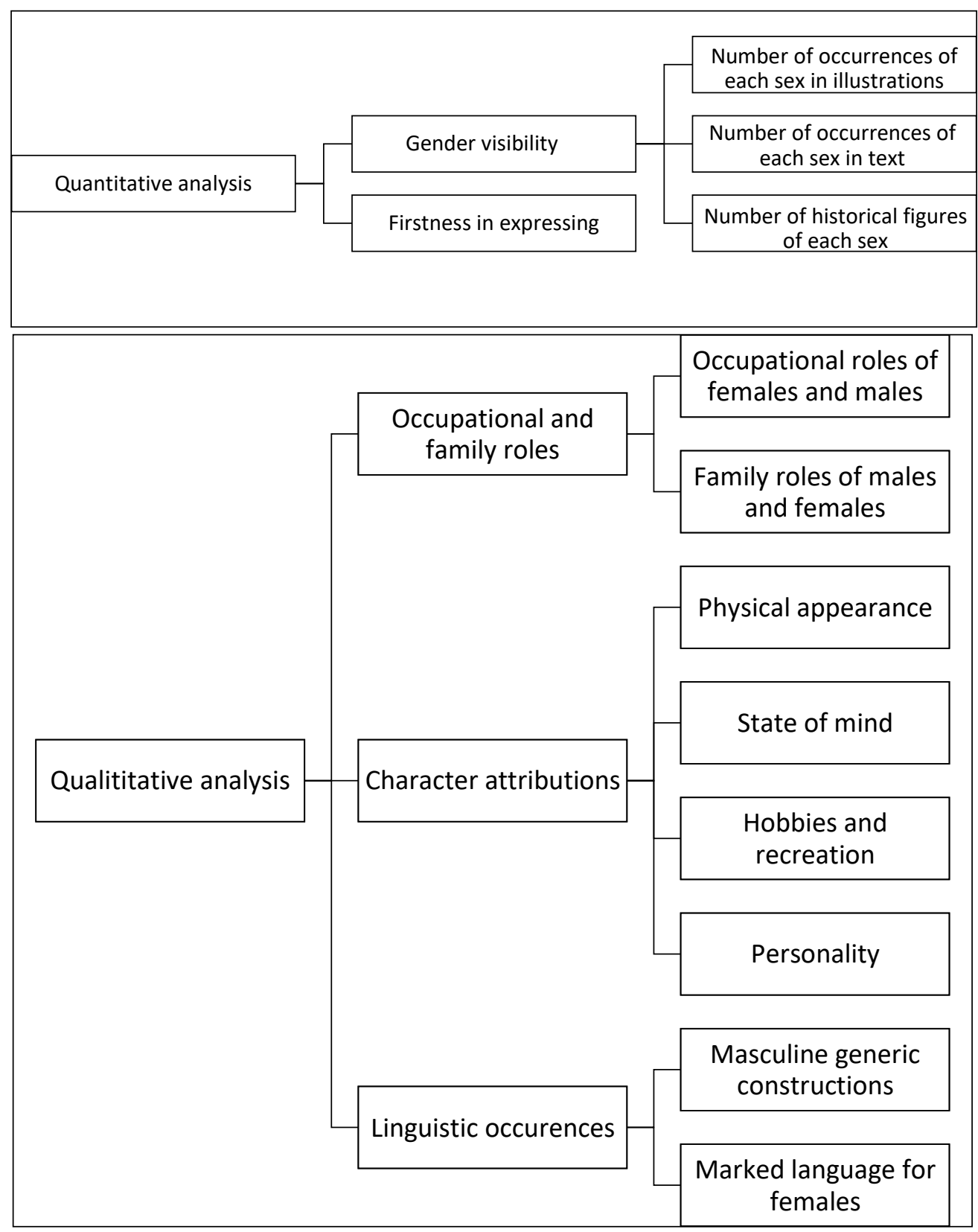

Figure 1: Categories of quantitative and qualitative analysis 
Under quantitative analysis, the text was analysed for gender visibility and firstness in expression. First, the frequency of occurrence of female and male characters in illustrations was tabulated, as well as the number of times each gender was mentioned in the text. Mentions in the text included characters depicted in dialogues, paragraphs, comprehension material, poems, examples and exercises. Gender visibility was also calculated in terms of the presence of male and female figures from history, mentioned in the text. Second, the firstness, i.e. the number of times females and males were mentioned first in the text, in instances where both the sexes are mentioned, was calculated.

The qualitative analysis comprised of a close reading of the text using Critical Discourse Analysis of Fairclough (2011). Under qualitative analysis, occupational roles of characters, family roles of characters and character attributions of males and females in the text were investigated for what they are and their underlying ideologies. Features of each sex in illustrations present in the textbooks were also analysed in this category to determine whether gender stereotyping was present. Finally, the text was studied for linguistic occurrences of usage of masculine generic constructions i.e. use of a masculine pronoun to mean both males and females. It was also studied for marked language for females i.e. instances where a linguistic element is distinctly identified or marked as female, while the regular form is used with a male (for example, actress vs actor).

\section{Results}

\section{Gender Visibility}

Number of occurrences in illustrations

Figure 2 indicates the frequency of number of illustrations in the text in each textbook. 


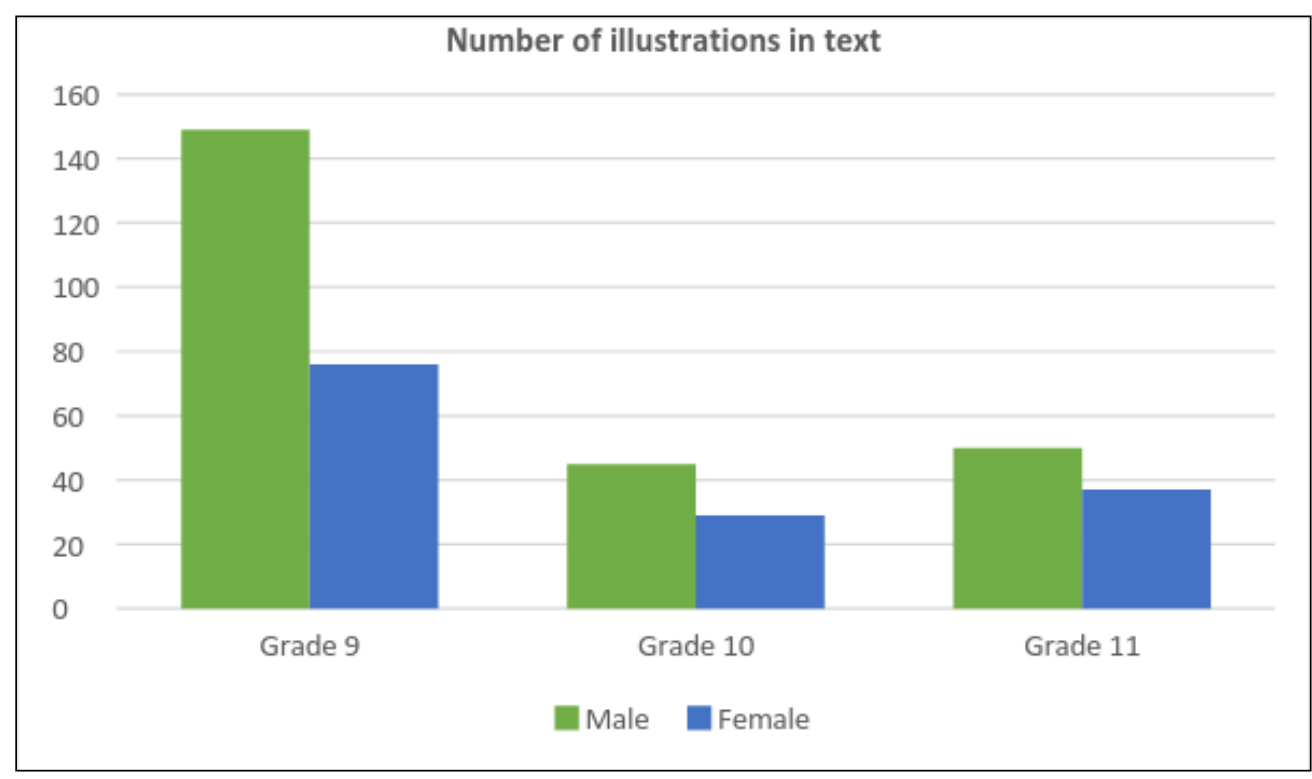

Figure 2: Number of illustrations in text

The Grade 9 textbook was observed to be the most discriminating because every unit had a higher ratio of males than females. Further, unit 4, "Getting About" had no illustrations of females at all. Similar to the number of characters (which is discussed in the next section), the number of illustrations in grade 10 textbook was comparatively low, with 9 out of 14 units not containing any figures in the illustrations, but scenery and art. In the 5 units that did contain illustrations, three had a higher frequency of male characters, one had more female illustrations and one had an equal number of illustrations for each sex. The higher number of female illustrations in unit 3 was mainly due to the illustration on page 26, of domestic chores. 5 out of 6 images were of females, engaging in different chores such as decorating a cake and polishing the floor (Refer Figure 4). In instances where females were illustrated, they were depicted in traditional - perhaps conservative - ways, dressed in saree, Kandyan saree, or in long skirts and blouses. Hair of females was observed to be either plaited or put up in a bun (Refer Figure 3). Males, on the other hand, were dressed in pants, t-shirts and shirts. The Grade 11 textbook was the most balanced out of the three, wherein two units contained an almost similar number of male and female characters. When calculating the ratio of illustrations of female to male characters in all three textbooks as a whole, the ratio is 1:1.5. 


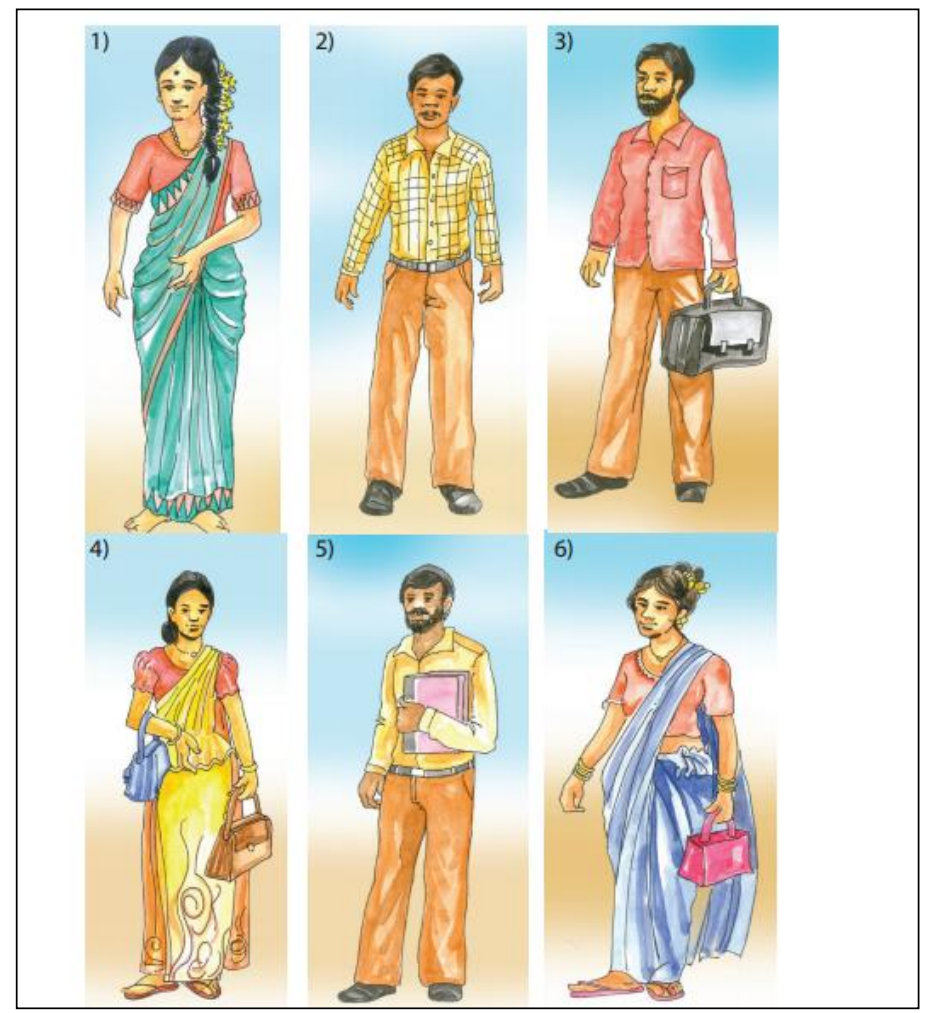

Figure 3: Attire as illustrated in an exercise (Source: English Textbook-Year 10, 2016, p.3)

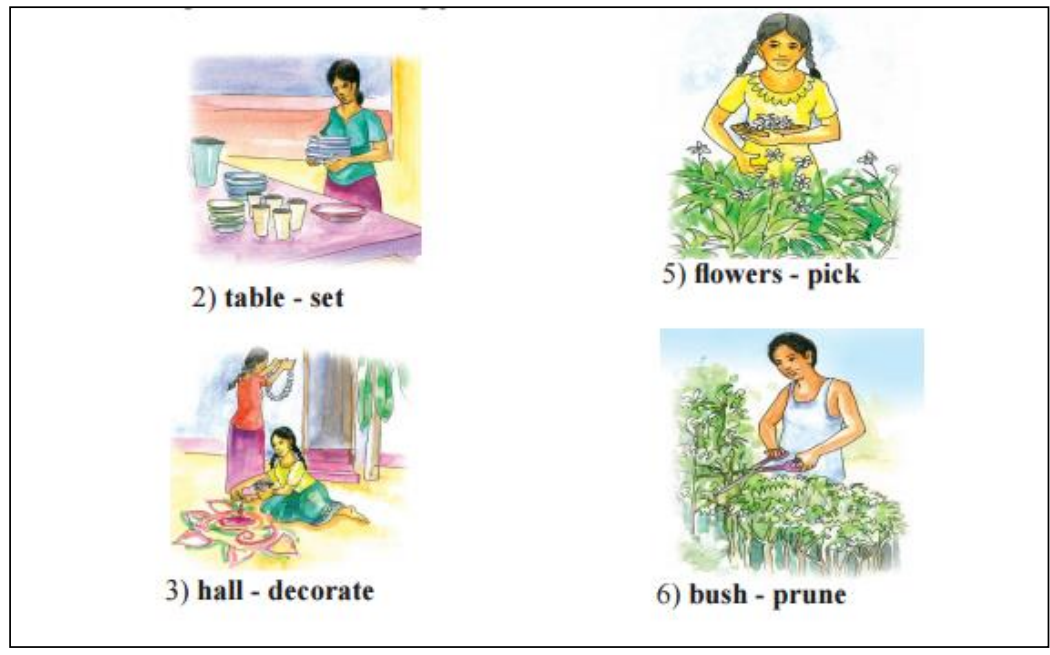

Figure 4: Chores as illustrated in an exercise

(Source: English Textbook- Year 10, 2016, p. 26) 
Number of occurrences of female and male characters

Number of occurrences of female and male characters in each of the textbooks is presented in Figure 5.

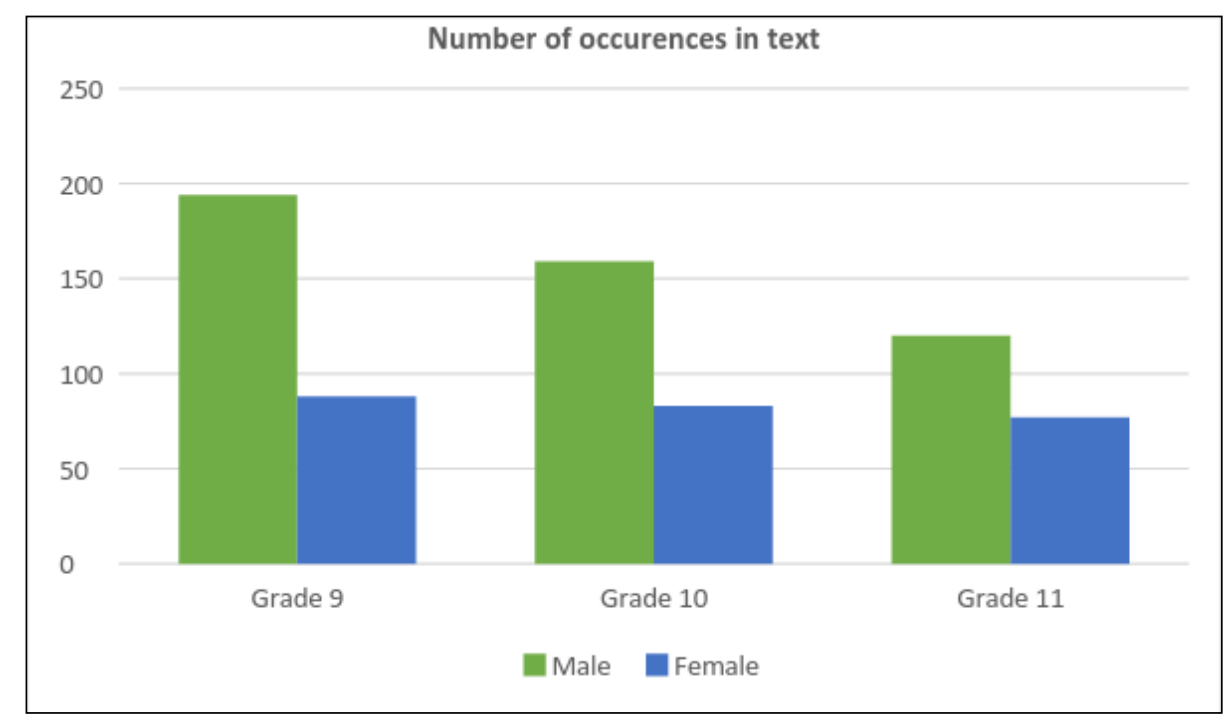

Figure 5: Number of occurrences in text

In Travelling:

In the grade 9 textbook, every unit had a higher frequency of male characters as opposed to female characters. The highest disparity between male and female characters was seen in the unit "Getting About", which focused on travelling. It was observed that males engaged in travelling while the few instances of female travel always included travel with a chaperone or male guardian.

In Myths and Fables:

Grade 10 textbook has a relatively lower number of overall characters, as it focuses more on topics such as information. However, there is a clear difference between the frequency of males and females mentioned in the text, with the highest disparity being recorded for unit 07, "Learning is Fun". This high frequency was mostly due to the inclusion of fables and myths in the unit which had male protagonists, and at times, purely male cast. 
In Relationships:

The grade 11 textbook is comparatively different because the first unit records a higher number of females than males it mentions in the text. However, the reason for this becomes rather evident when realising that the unit is "Relationships", where females are given more exposure in terms of establishing and maintaining relationships. Conversely, a number of female characters in the text are identified in relation to the male character. For instance, "Mr. Nadaraja's wife" and "Nehru's wife" are two characters that are alluded to in relation to their husbands, without being named in the text. When taken as a cumulative, the three textbooks depict a clear preference for male characters over female characters, with a ratio between female characters to male characters of 1:1.9.

\section{Number of historical figures}

Figure 6 illustrates the frequency of occurrence in female and male historical figures across the three textbooks.

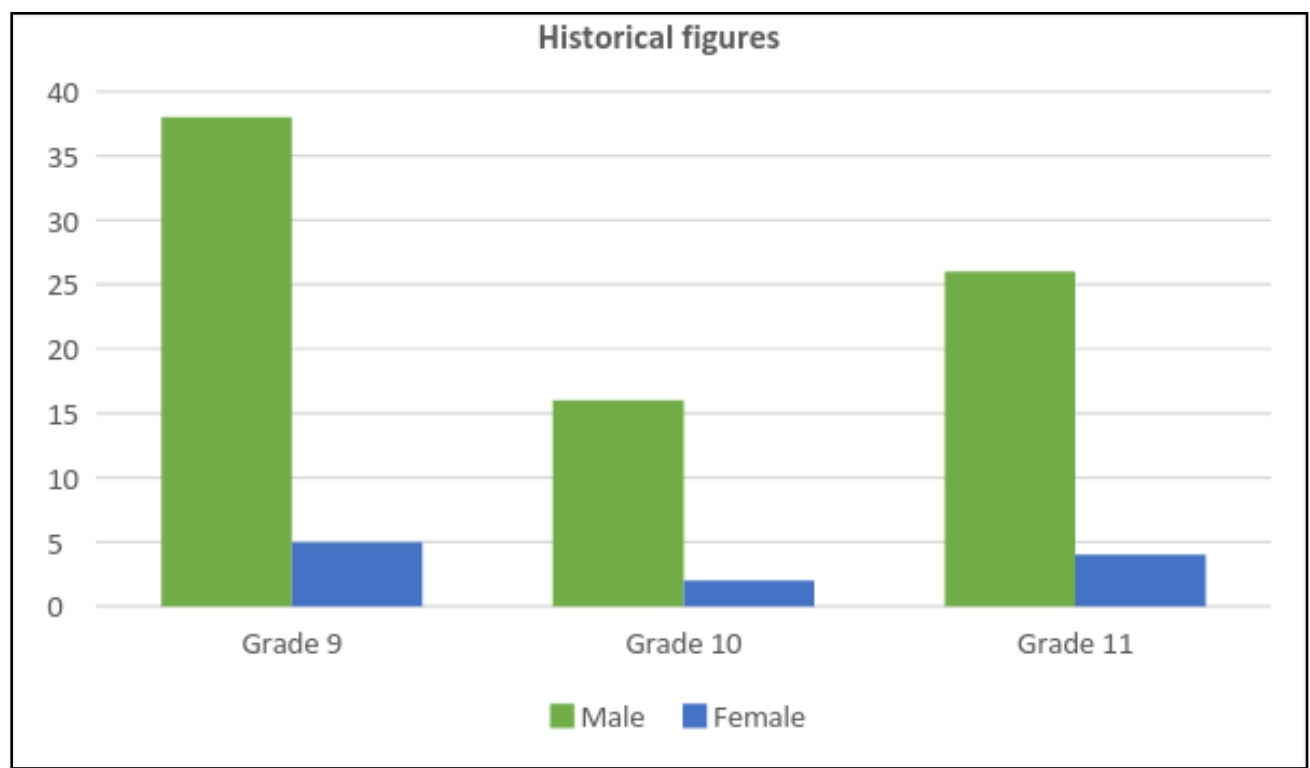

Figure 6: Historical Figures

The presence of female figures was minimal in all three textbooks, with none reaching double figures. Compared to the high number of male figures this 
disparity stands apart. The male figures were from different eras of history, in different fields, compared to which the diversity of female figures was low.

\section{Firstness in expressing}

Firstness is where masculine pronoun/noun is placed before the feminine pronoun/noun, which according to Hartman and Judd (1978) "reinforces the second place of the woman". Figure 7 illustrates the frequency of firstness in occurrence with regard to masculine and feminine pronouns.

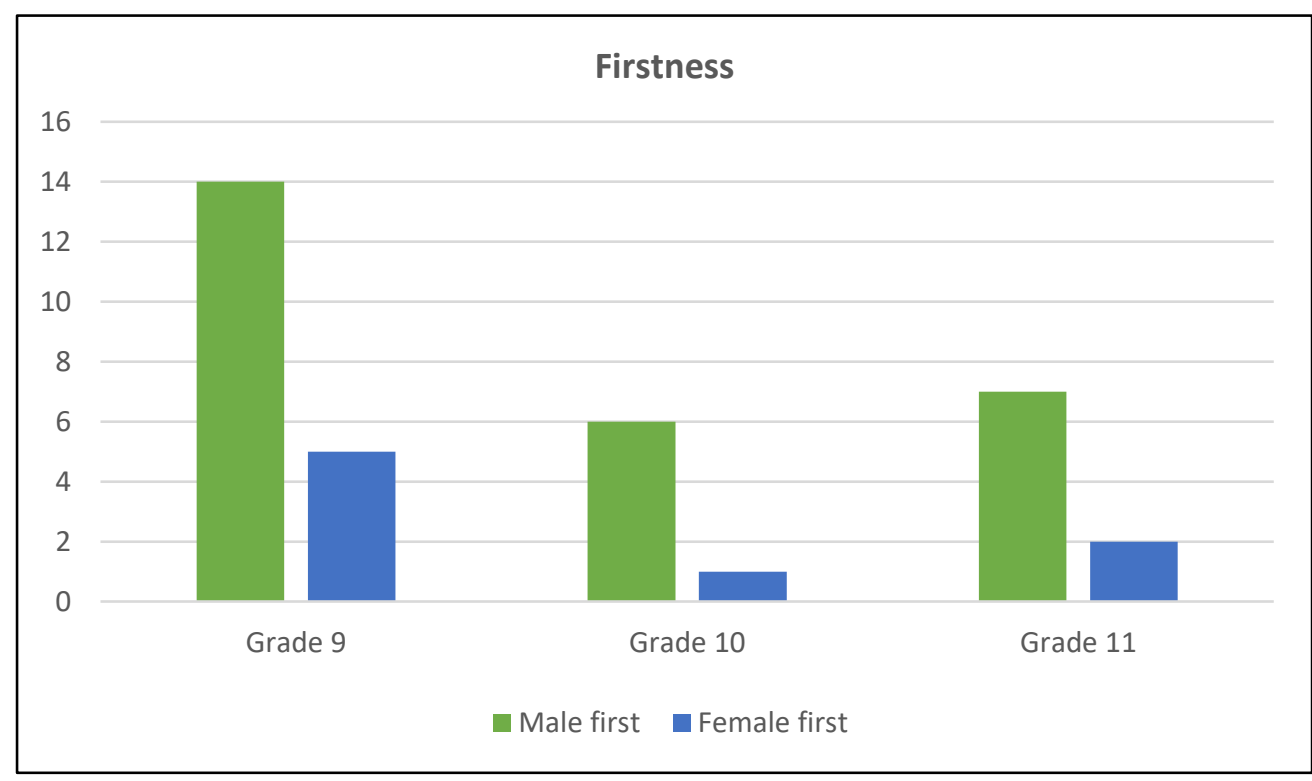

Figure 7: Firstness in expressing gender pronouns

As is illustrated in the chart "Firstness", males were mentioned first more than females in all three textbooks. The most common occurrences were his/her and him/her. In instances where the females were mentioned first, they were "mother and father", "ladies and gentlemen" and "bride/bridegroom". It can be deduced that the overall ratio of female to male firstness in the text is at 1:3.3.

\section{Occupational and Family Roles}

Occupational roles displayed a partiality towards the male, not only through the expression of occupational roles men are engaged in but also when discussing the jobs a boy would like to be engaged in, the diversity being 
higher than that of a girl expressing the same. A comprehensive list of these occupational roles prescribed to males and females is provided in Table 1. It was also observed that in most instances of mentioning the word "teacher" with regard to the English language, the teacher was assumed a female, while teachers of science and information technology were clearly defined as male.

Table 1: A list of occupational roles prescribed to males and females

\begin{tabular}{|l|l|}
\hline Occupational roles for males & Occupational roles for females \\
\hline Assistant Accountant & Athlete \\
Astronaut & Ballerina \\
Athlete & Empress \\
Bacteriologist & Housewife \\
Boss & Inventor \\
Bus conductor & Princess \\
Editor & Queen \\
Engineer & Receptionist \\
Environmentalist & Stay-at-home-mother \\
Explorer & Teacher \\
Hotel manager & Writer \\
Inventor & \\
Journalist & \\
King & \\
Lecturer & \\
Literary critic & \\
Mayor & \\
Mechanic & \\
Philosopher & \\
Photographer & \\
Physiologist & \\
Pilot & \\
Poet & \\
Prince & \\
Psychologist & \\
Ruler & \\
Sailor & \\
Science teacher & \\
Shop owner & \\
Soldier & \\
Surgeon & \\
Writer & \\
Zoo manager & \\
\hline
\end{tabular}


A number of characters in each textbook was represented in family roles, ranging from parents to uncles to grandparents. "Mother" was often the subject of female mentions in exercises, while "wife" was the most common in reading paragraphs and stories. "Father" was mentioned in instances that required purchasing of an item and/or instances that required travelling. "Uncle" was mentioned a considerable number of times, mainly in relation to imparting new information. In addition to the above, family roles such as sister, brother, grandmother, grandfather and cousins were present in the texts. Interestingly, no mention of "husband" was to be found in the text. When calculated overall, the most common family role was "mother", with "father" coming in at second. The lowest number of mentions in a major family role was for "daughter".

\section{Character Attributes}

The character attributes were often deduced from the texts in the textbooks as more often than not, there were no specific character attributions clearly defined for each sex. Some of the observations that were common to all three texts were that in dialogues, males always played the role of the knowledge leader i.e. the one with the information, while the females played a supporting role (Refer Figure 3); males were portrayed as being more interested in sports and physical activities such as camping while females were depicted as interested in domestic activities such as reading; and the utterances by females focused more on exclamations, appreciations and observations as opposed to that of males. 


\begin{tabular}{|c|c|}
\hline & The Underwater World \\
\hline Naween & $\begin{array}{l}\text { - Have you ever thought that there's a world under water? Now I am } \\
\text { taking you to that wonderful world. Get ready to dive into the ocean.Look } \\
\text { at this. What do you think this } \\
\text { is? }\end{array}$ \\
\hline Velu & $\begin{array}{l}\text { - What a beautiful scene! It is } \\
\text { the sea bed, isn't it? }\end{array}$ \\
\hline Naween & $\begin{array}{l}\text { - Yes it is. Deep in the sea bed, } \\
\text { there are hundreds of } \\
\text { shipwrecks including the } \\
\text { famous Titanic and ruins of } \\
\text { early civilisations. }\end{array}$ \\
\hline Yoosuf & - How beautiful they look! \\
\hline Naween & $\begin{array}{l}\text { - But, these are artificial things, The natural things are the most picturesque. } \\
\text { Now look at this. These are coral reefs. }\end{array}$ \\
\hline Lasini & - They're wonderful, aren't they? \\
\hline Naween & $\begin{array}{l}\text { - Yes. Coral reefs and a great variety of animal and plant life beautify the } \\
\text { underwater world. Coral reefs are structures produced by nonliving } \\
\text { organisms that have decomposed into fossil. }\end{array}$ \\
\hline Malindu & :- I've heard that coral reefs are not found everywhere. \\
\hline Naween & $\begin{array}{l}\text { - That's true. Although corals are found both in temperate and tropical } \\
\text { waters, reefs are formed only in a zone from } 20^{\circ} \text { North to } 20^{\circ} \text { South of } \\
\text { the equator. Reef forming corals do not grow at depths of over } 30 \mathrm{~m} \text { or } \\
\text { where the water temperature falls below } 11^{\circ} \mathrm{C} \text {. }\end{array}$ \\
\hline Lasini & :- Look how these fish swim about the corals! \\
\hline
\end{tabular}

Figure 8: Conversation between students during class (Source: English Textbook- Year 9, 2016, p. 46)

Female physique is given attention in the grade 10 textbook. The girls are depicted as being unsatisfied with their natural appearance - "I wish I had long wavy hair like her" - and are shown to notice external appearances. There is no comparison to the physical appearance or opinion of personal appearance from a boy in the text. The boys are illustrated as having a wide range of emotions, such as helpful, cheerful, moody, friendly and aggressive. In contrast, girls are depicted with only a few emotions such as confident, sensible and shy. 
When taken as a whole, the range of characteristics attributed to males was a larger range than that of females. Females were often portrayed in passive roles of reading, borrowing books and gardening, and were created as more emotional and family-oriented characters. The males, on the other hand, were portrayed in active roles of playing sports and providing for the family and were created as not only emotional and family-oriented characters but also as characters with social responsibility.

\section{Linguistic occurrence of sexism}

In recent years a good deal of activity has focused on the generic use of the pronoun he...involving in sex/gender distinctions...Arguments have used linguistic data as evidence to prove (or deny) that the language manifests the sex-based biases of the society. The evidence has been used for (or against) proposals to reform the language by replacing generic he with he or she, he/she, s/he, they, etc. (Bendix, 1979, p. 23)

The linguistic occurrences of sexism in the textbooks were sought for in two specific areas: marked language for females i.e. using a marked or distinct term to indicate the gender of the subject (for an example, using "monitress", implying that all instances where "monitor" is mentioned it refers to male) which has negative connotations in numerous instances, such as when using "master" vs "mistress"; and masculine generic constructions i.e. using a male pronoun to indicate a group which comprises not only of men (for example, "mankind").

All three textbooks were free of using marked language for females for the most part. The grade 11 textbook, though, recorded two instances of the category - "monitress" and "goddess". However, masculine genetic constructions were rather frequent in all three textbooks. "Man" and "mankind" were the most common uses of the male pronoun as the generic, especially in units that discussed environment and future. In addition to the above, there were mentions of "sportsmen", "tribesmen" and "man-made" in the text. However, there were instances of using "human" - grade 11 mentions "human population" ( $p$ 45) and "human error" ( $p$ 107). There were also attempts, to a certain degree, to remove gender connotations from topics in the writers often repeating "the manager" throughout the sentence instead of using a pronoun. 


\section{Discussion}

In each of the categories analysed - gender visibility, firstness in expression, occupational and family roles, character attributes, and linguistic occurrence - there is evidence to believe that ESL textbooks in Sri Lanka, too, follow the trend of textbooks analysed in other countries, as males are constructed as more powerful, authoritative, famous, and above all visible contributors to the society.

The simple matter of having twice as many male characters/occurrences as that of females show males to be dominating the social sphere. However, according to the World Bank Report (2014) $51.75 \%$ of the Sri Lankan population is female; according to the Department of Consensus (2013) $35.9 \%$ of women were economically active. Not only were the mentions of females lower in terms of numerical value, it was also deduced that males simply dominate the content. It propagates the idea that females are to play a merely supportive role in the social context, while males are to carry society forward. Embedding such an ideology in the minds of the adolescent could result in females being relegated to an almost invisible role within the school context as well.

The findings of the unit "travelling" was an apt portrayal of Sri Lankan cultural "values", although these values are ones that are being questioned within the current social context, as is discussed in “The 'Women's Question' in Sri Lanka: A Reflection in 2017" by Wijesiriwardena (2017). It promotes the expired notion of females being restricted to the home, while the man is to venture forth into the world.

Most of the fables and myths revolved around men and their heroic deeds in the unit titled "Learning is Fun", while females were often merely an accessory. The Two Frogs (Greek fable), Plucking up a Crop to Help it Grow (Chinese fable), Honour, Fire and Water (French fable), Education of the Young Lion (Russian fable) all have a male - either human or animal - as the protagonist. The myths included Bhigru and the Three Gods, and Orpheus and Eurydice where men played the main role once again. If one is to assume that the purpose of fables, myths and legends is to propagate culture and values, this phenomenon places the texts in a problematic situation. The 
problem here lies in the choice of texts, which have failed to grasp that inclusion of female protagonists is necessary when presenting a story to the young learner as stories shape who a person is; stories, as is evident through the history, is a way of shaping perceptions and continuing heritage. The current choice of texts seems to indicate that it is the males who are solely responsible for the propagation of these cultural values, and for shaping the world.

This ideology was further aided by the illustrations, which were at a female: male ratio of 1:1.5. The instances where females were illustrated they were often in sarees, which is a traditional notion that is not a common occurrence in the current society. Unless engaged in a particular calibre of work, or attending a function, females of the modern society rarely wear the saree in their day to day life. When compared to males, who are never illustrated in the national attire, but always in pants and shirts/t-shirts, the question of discrimination in attire as represented in the text is evident. However, this closely ties in with the notion of woman as a bearer of culture, which has been explored by both Jayawardena (1986/2009) and De Mel (2001). These provide unrealistic notions of appearance for the young learners who are studying these texts, as it would instil in them the idea that what is presented in the book is what is appropriate.

Historical figures in textbooks serve as role models for students (Tao, 2008). In all the three textbooks, the number of female role models was limited when compared to the wide range of male role models provided. In this regard, the Sri Lankan ESL textbooks were similar to those of other countries where females were not given sufficient exposure for their achievements and mark they have left in history. If the characters are to be role models for the learners, it is only right that there be a sufficient range of models for both the sexes. It was interesting to note that in one lesson, when a girl was asked to select a role model, she picked "Charlie Chaplin". The problem here lies not with the child choosing a male, but with the idea that it subtly conveys: a female has never made it into the world of comedy to warrant a young learner's attention. The inclusion of a popular female comedian from history like Phyllis Diller, or even Sri Lanka's own Mercy Edirisinghe who was a comedian along much the same strain as Chaplin, albeit in speaking roles, would have broadened the view of the young learner. 
As historical figures included those of Gods, a cultural element of Sri Lanka could be strongly sensed here. In terms of historical figures, where Maha Maya Devi was mentioned in the text, it was presented in relation to being the mother of Prince Siddhartha, and not in her own right. Even the story focused on the conceiving of the prince, and thus the female character was made a tool in a story where the protagonist has not even been born yet.

It is also problematic that years after the researcher herself has finished formal school education, "Marie Curie" still takes centre stage as a key female role model. After decades of development and evolution, it is but to be expected that these texts would include contemporary role models. It is not a lack of female role models in the real world that has brought out this phenomenon; one would believe that a person such as Maya Angelou would warrant mentioning in the textbooks considering her contribution towards literature. And yet, all the female models mentioned in the text are truly historical resulting in the possibility of the learners simply overlooking their presence as they have been mentioned repeatedly over the years. The root issue with this unjust representation is the painting of a false picture to the young mind that females have accomplished nothing when compared to men.

All three textbooks contained instances where the masculine noun/pronoun was used prior to the feminine noun/pronoun, which illustrates the normality of male being the dominant sex. The only instances of female firstness were as a result of cultural norms as well, in the case of "mother and father", "bride and groom", and "ladies and gentlemen". The above suggests that females are before males if they are mothers, brides or "ladies". The most frequently heard manner of uttering the analysed words are what was written in the texts, which illustrates that the text is but a reflection of the ideologies of the society when it comes to being the prominent sex.

Ideologies of the society were further reflected in the occupational roles for males and females. The diversity of occupations for males clearly illustrated that it is still accepted that the main provider needs to be male. This sex segregation in terms of occupations can severely hinder possible ambitions of young learners who are exposed to these texts. With regard to ambitions, in the unit "dreams and ambitions" the only professional role girls are described in are ballerinas. This slight has severe implications. This restricts the young girls to an appearance based career, which in fact is not 
professionally practised in the country. When compared to the actual diversity of occupations that females are engaged in the society at large, the representation in the textbooks can be said to be woefully inadequate.

Contrary to the foreign texts such as Iranian as well as the USA where the male was not given a prominent role in the family, the Sri Lankan textbooks provide if not equal, then almost equal importance to the role of the father. This is both a positive as well as a negative. It is a positive because the learners would be exposed to the role of the male in the family, and would not alienate the father. However, the negative of this lies in the establishment of the father's role as a provider in the texts. It is the father who takes the children out and buys them things, and no evidence could be found in the text for an emotional attachment between the father and the children. Further, the implied establishment in the texts of the mother being at home while the father provides could lead to psychological issues in the children who would expect the same from their families.

It also has to be noted that no male character was given any attribution related to domestic work, while females were often described as "enjoying cooking" and having a hobby of making sweets. The character attributes showed clear sex segregation, not as significantly in emotions, as was the case in most of the studies in China and USA, but in terms of their mental capacity and interests. The character attributes were in line with the established gender roles in the society and expressed them as the norm. The main concern in this type of (mis)information is that a learner who is, in fact, different would feel themselves an alien. However, the text has to be commended for almost equal distribution of emotions among the sexes.

Linguistically, though, the textbooks have attempted to be universal in not using marked language for females, and in trying to avoid the use of masculine generic constructions. However, it must be noted that use of "human" as opposed "man", and "humankind" as opposed to "mankind" being present in the text indicates a non-uniformity in the writing itself, which only highlights the instances where masculine generic constructions are used. While there still were instances of regarding male as the default sex, the fact that apparent attempts were made to avoid doing so shows a positive trend. 


\section{Conclusion}

The textbooks provided by the government of Sri Lanka for grades 9, 10 and 11 were analysed to identify whether the content was sexist or not. It was discovered that the visibility of both genders was not equal and that males were twice as visible as females. Males were presented with a larger range of occupational roles, where the father was a key figure in the text. Men were featured as more active, knowledgeable and smart while females were relegated to a secondary, passive role. This secondary role of females was further stabilised by the high frequency of male firstness. However, the texts attempted to keep away from male generic pronoun which could be identified as a step in the correct direction.

It needs to be noted that the above results are limited as only three textbooks were studied. In the texts that were studied, listening passages were not given, therefore those activities were not focussed upon in this study. Further, it needs to be noted that these textbooks are used only by government schools, and as such cannot be considered a verdict on the entire education system of Sri Lanka as a whole because the international schools in the country which cater to a small minority of the student population have supplementary material and follow a different set of textbooks.

Forty years after the first ever study on sexism in textbooks was conducted in the USA, a study of selected textbooks from Sri Lanka illustrates that sexism in language is still very much present in modern day textbooks. This creates a dire situation in the field of ESL education as the world discovered by the learner via language is a sexist, unrealistic one. The long term solution to this would be to revise the textbooks to be more gender inclusive. Until such a reform is reached, the English teacher is left with a higher purpose, to supplement the text and explain the content to the young learner in such a manner that the mind of the learner is open to embracing equality through the learning of language of the world. 


\section{References}

Ansary, H., \& Babaii, E. (2005). Subliminal sexism in current ESL/EFL textbooks. In P. Robertson, English language learning in the Asian context (pp. 184-192). Tortola, British Virgin Islands: Asian EFL Journal Press.

Bahman, M., \& Rahimi, A. (2010). Gender representation in EFL materials: an analysis of English textbooks in Iranian high schools. Procedia Social and Behavioral Sciences, 9 (1). 273-277.

Bendix, E. H. (1979). Linguistic models as political symbols: Gender and the generic "he" in English. Annals of the New York academy of sciences, 327(1), 23-39. doi:10.1111/j.1749-6632.1979.tb17750.x

De Mel, N. (2001). Women \& the nation's narrative. Colombo: Social Scientists' Association.

Department of Census and Statistics. (2013). Sri Lanka labour force statistics. Ministry of finance and planning, Department of census and statistics. Colombo: Ministry of finance and planning. Retrieved from http://www.statistics.gov.lk/samplesurvey/LFS_Q3_Bulletin_2013.pdf

Ebadi, S. (2015). Investigating gender representation in Iranian EFL textbooks. English for specific purposes world, 16.

Esen, Y. (2007). Sexism in school textbooks prepared under education reform in Turkey. Journal for critical education policy studies, 5(2), 15-43.

Evans, L., \& Davies, K. (2000). No sissy boys here: A content analysis of the representation of masculinity in elementary school reading textbooks. Sex roles, 42(3), 255-270.

Fairclough, N. (2001). Critical discourse analysis as a method in social scientific research. In R. Wodak, \& M. Meyer, Methods of critical discourse analysis (pp. 121-138). London: SAGE Publications.

Hartman, L., \& Judd, E. L. (1978). Sexism and TESOL materials. TESOL quarterly, 12(4), 383-393. doi:10.2307/3586137

Hellinger, M. (1980). 'For men must work, and women must weep': Sexism in english language textbooks used in German schools. Women's Studies International Quarterly, 3(2), 267-275.

Jayawardena, K. (2009). Emancipation and subordination of women in Sri Lanka. In K. Jayawardena, Feminism and nationalism in the third world (3rd ed.)( pp. 107-133). Colombo: Social Scientists Association.

Ndura, E. (2004). ESL and cultural bias: An analysis of elementary through high school textbooks in the Western United States of America. Language, culture, and curriculum, 17(2), 143-153. 
NietoGomez, A. (2014). La Chicana: Legacy of suffering and self denial. In A. M. Garcia (Ed.), Chicana feminist thought: The basic historical writings (2nd ed., pp. 48-50). New York: Routledge.

Pavlenko, A., Blackledge, A., Piller, I., \& Teutsch-Dwyer, M. (2001). Multilingualism, second languge learning, and gender. New York: Mouton de Gruyter.

Perera, M. (2010). Coping with student heterogeneity in the English language classrooms. Colombo: National Education Commission.

Porreca, K. (1984). Sexism in current ESL textbooks. TESOL quarterly, 18(4), 705-724.

Salyers, F., \& McKee, C. (2007). The young adolescent learner. Annenberg Media. Retrived from

https://www.learner.org/workshops/middlewriting/images/pdf/W1Rea dAdLearn.pdf

Tao, B. (2008). Identifying and combating sexim in EFL textbooks - with a case study into China. ERIC article ED5020111 Retrieved from http://www.eric.ed.gov/ERICWebPortal/search/detailmini.jsp? nfpb=tr ue\& \&ERICExtSearch SearchValue 0=ED502011\&ERICExtSearch Searc hType 0=no\&accno=ED502011

Taylor, F. (2003). Content analysis and gender stereotypes in children's books. Teaching sociology, 31(3), 300-311.

The World Bank. (2014). Population, female. Retrieved from http://data.worldbank.org/indicator/SP.POP.TOTL.FE.ZS?locations=LK\&V iew=chart

Werner, O. (1997). Sapir-Whorf hypothesis. In P. V. Lamarque (Ed.), Concise encyclopaedia of philosophy of language (pp. 76-83). Exeter: Pergamon.

Wijesiriwardena, S. (2017). The 'women's question' in Sri Lanka: A reflection in 2017. Shishta Lanka, 1, 1

Wolf, M. (2007). Proust and the squid: The story and science of the reading brain. New York: Harper Collins. 